TECHNICAL TRANSACTIONS 7/2018

MECHANICS

DOI: $10.4467 / 2353737$ XCT.18.107.8802 SUBMISSION OF THE FINAL VERSION: 4/07/2018

\author{
Rafał Gałek (rafalgalek@prz.edu.pl) \\ Department of Thermodynamics, Faculty of Mechanical Engineering and Aeronautics, \\ Rzeszow University of Technology
}

\title{
TWO-DIMENSIONAL NUMERICAL SIMULATION OF A THERMOELECTRIC COOLER MODULE
}

DWUWYMIAROWA SYMULACJA NUMERYCZNA MODUEU
CHEODZIARKI TERMOELEKTRYCZNEJ

\begin{abstract}
The paper presents the methodology and results of a numerical simulation of coupled thermal and electrical phenomena in a thermoelectric (TE) cooler module obtained with the MOOSE Framework released by Idaho National Laboratory. The coupled system of partial differential equations is solved for the value of electric potential and temperature fields. Equations include contributions from electric conduction, Seebeck effect, thermal conduction, Joule heating as well as Peltier and Thomson effects. The values of the cooling capacity and the voltage drop of the module are calculated and compared with the data provided by the manufacturer of the thermoelectric cooler in order to determine if the simplified assumptions adopted in the numerical model are appropriate to reliably infer about the performance of the TE module composed of over one hundred thermoelectric pairs.

Keywords: thermoelectrics, Peltier effect, Thomson effect, Seebeck effect, numerical simulation, MOOSE
\end{abstract}

\section{Streszczenie}

Artykuł prezentuje metodologię i wyniki symulacji numerycznej zjawisk cieplnych i elektrycznych w module chłodziarki termoelektrycznej otrzymane przy użyciu środowiska MOOSE Framework. Układ równań różniczkowych rozwiązano dla szukanych wartości potencjału elektrycznego oraz temperatury. Sformułowane równania uwzględniają przewodzenie prądu elektrycznego, efekt Seebecka, przewodzenie ciepła, generację ciepła Jouléa oraz efekty Peltiera i Thomsona. Otrzymane wartości wydajności chłodniczej orazspadku napięcia modulu zostały porównane ze specyfikacją opublikowaną przez producenta urządzenia w celu oceny, czy przyjęte w modelu numerycznym założenia upraszczające pozwalają poprawnie określić wydajność modułu złożonego z ponad stu par termoelektrycznych.

Słowa kluczowe: zjawiska termoelektryczne, efekt Peltiera, efekt Thomsona, efekt Seebecka, symulacja numeryczna, MOOSE 


\section{Introduction}

Thermoelectric devices (TEs) have gained a considerable amount of popularity in recent years in cooling applications for electronic components and portable equipment. Their purely electrical (solid state) principle of operation offers some significant advantages over traditional refrigerators. TEs have no moving parts, therefore problems with friction wear, noise or vibration do not exist. The lack of a fluid refrigerant avoids safety issues regarding potentially toxic leaks. A compact design of commercially available thermoelectric modules makes them useful in portable equipment and allows an easy arrangement of serial, parallel or mixed configurations. A single thermoelectric pair is composed of a p-type and an n-type semiconductor as well as a thin copper interconnector. In order to meet performance requirements such as cooling capacity or operating voltage, a number of thermoelectric pairs are assembled together to form a TE module.

The scope of application of thermoelectric coolers (TECs) covers instances where cooling power demand is generally not extensive and where greater emphasis is placed on portability, reliability and the precise control of cooling performance [1]. Such characteristics make them particularly suitable for cooling electronic components [2] including even the elements of power electronics circuits [3]. Besides general-purpose electronic equipment, thermoelectric coolers have proved to be useful in more specialised devices such as cryoprobes for cryosurgery [4], infrared cameras [5] and mid-infrared interband cascade lasers [6]. The increasing popularity and availability of TE devices encourages researchers to seek even more unexpected applications for thermoelectric coolers; this is exemplified by the concept of thermoelectrically cooled protective suits for firefighters presented in [7].

Numerical simulations may assist in the design process of TE devices and help to assess their properties prior to actual manufacturing. The required functionality for performing such calculations is present in some commercial numerical software applications such as COMSOL Multiphysics and ANSYS. The other solution is to implement the governing equations and solver in any programming language that offers support for the required mathematical operations. Such a model using two-dimensional approximation and finitevolume discretisation was presented in [8]. The authors however used entirely custom-made code, therefore reproduction of their results would require considerable programming effort. A similar custom model may be found in [9] for full 3D geometry, but unfortunately, the authors did not provide many details on the numerical scheme that was used.

Employing commercial numerical software to solve equations governing thermoelectric phenomena in TEs seems to be a more popular approach. In [10] and [11], ANSYS software was used in the performance analysis of a thermoelectric cooler. The solution was not limited to a single TE pair with the assumption of periodicity, therefore the computational domain comprised full $3 \mathrm{D}$ representation of every thermocouple in the module in order to appropriately account for scaling effects. The application of COMSOL Multiphysics for thermoelectric calculations is also reported in [12], however a thermoelectric generator was considered instead of a TE cooler.

Both approaches to the problem mentioned above have their own shortcomings: commercial software packages are fairly expensive while programming a solution algorithm from scratch 
may be difficult and time consuming. The present work therefore takes an intermediate solution: governing equations are implemented and solved in an existing numerical environment - the MOOSE (Multiphysics Object-Oriented Simulation Environment) Framework [13] released by Idaho National Laboratory under the LGPL 2.1 license.

The results of numerical simulations for wide range of operating temperatures and electric currents are compared with those provided in the datasheet published by the manufacturer of thermoelectric cooler [14] in order to assess the validity of the adopted model.

\section{Problem statement}

\subsection{Governing equations}

The numerical simulation of a thermoelectric device requires a solution of coupled system of partial differential equations (PDE) that describes the mutually interacting thermal and electric phenomena present in the domain of interest. Such a solution should then consist of spatial distributions of electric potential $\varphi$ and temperature $T$. The electric potential distribution may be found on the basis of the current continuity principle:

$$
\nabla \cdot \boldsymbol{J}=0
$$

where $\boldsymbol{J}$ is the current density vector and $\nabla \cdot$ is the divergence operator.

In thermoelectric devices, the current density may be expressed as [15]:

$$
J=-\sigma \nabla \varphi-\sigma \alpha \nabla T
$$

where $\sigma$ is the electric conductivity, $\alpha$ is the Seebeck coefficient and $\nabla$ is the gradient operator. The first term on the right side of equation (2) is current density due to electric conduction; the second term is related to the Seebeck effect. By substituting (2) into (1), one can obtain a PDE describing the distribution of the electric potential:

$$
-\nabla \cdot(\sigma \nabla \varphi)-\nabla \cdot(\sigma \alpha \nabla T)=0
$$

The temperature distribution must satisfy the heat equation with additional source terms resulting from the very nature of the thermoelectric device:

$$
\nabla \cdot \boldsymbol{q}=Q_{J}
$$

where $q$ is the heat flux vector and $Q$ is the Joule volumetric heat source. In thermoelectric phenomena, heat flux comprises not only the heat conduction term but also the term responsible for Peltier and Thomson effects [15]:

$$
\boldsymbol{q}=-\lambda \nabla T+\alpha T \boldsymbol{J}
$$

where $\lambda$ is the thermal conductivity. Joule heat source may be expressed as:

$$
Q_{J}=-J \nabla \varphi
$$


The substitution of (2), (5) and (6) into (4) results in the heat transfer equation:

$$
-\nabla \cdot(\lambda \nabla T)-\nabla \cdot\left(\sigma \alpha T \nabla \varphi+\sigma \alpha^{2} T \nabla T\right)-\sigma \nabla \varphi \cdot(\nabla \varphi+\alpha \nabla T)=0
$$

The first term on the left side of the equation (7) is responsible for heat conduction, the second term comprises contribution from the Peltier effect while the third term describes Joule heating. Furthermore, it was demonstrated in [16] that with the temperature-dependent Seebeck coefficient, the second term in equation (7) also accounts for the Thomson effect.

The numerical framework used to solve a system of coupled partial differential equations (3) and (7) in this work requires them to be expressed in a so-called weak form. To obtain such a formulation, the strong form of PDE has to be multiplied by test function $\psi$, integrated over the domain $\Omega$ and rearranged with the application of the divergence theorem to yield the final expression comprising both volume and boundary integrals. The execution of such a procedure on equations (3) and (7) results in their respective weak formulations:

$$
\begin{gathered}
\int_{\Omega} \sigma \nabla \varphi \cdot \nabla \psi \mathrm{d} \Omega-\int_{S} \sigma \nabla \varphi \cdot \boldsymbol{n} \psi \mathrm{d} S+\int_{\Omega} \sigma \alpha \nabla T \cdot \nabla \psi \mathrm{d} \Omega-\int_{S} \sigma \alpha \nabla T \cdot \boldsymbol{n} \psi \mathrm{d} S=0 \\
\int_{\Omega} \lambda \nabla T \cdot \nabla \psi \mathrm{d} \Omega-\int_{S} \lambda \nabla T \cdot \boldsymbol{n} \psi \mathrm{d} S+\int_{\Omega} \sigma \alpha T \nabla \varphi \cdot \nabla \psi \mathrm{d} \Omega-\int_{S} \sigma \alpha T \nabla \varphi \cdot \boldsymbol{n} \psi \mathrm{d} S+ \\
+\int_{\Omega} \sigma \alpha^{2} T \nabla T \cdot \nabla \psi \mathrm{d} \Omega-\int_{S} \sigma \alpha^{2} T \nabla T \cdot \boldsymbol{n} \psi \mathrm{d} S-\int_{\Omega} \sigma \nabla \varphi \cdot \nabla \varphi \psi \mathrm{d} \Omega+ \\
-\int_{\Omega} \sigma \alpha \nabla T \cdot \nabla \varphi \psi \mathrm{d} \Omega=0
\end{gathered}
$$

where $\boldsymbol{n}$ is a unit vector normal to the surface.

The application of the divergence theorem allowed avoiding higher derivatives (i.e. Laplacian) in diffusion terms and yielded boundary integrals (denoted as integral over $S$ ) describing the boundary conditions of the problem. The integrals over domain $\Omega$ are the basis for the formulation of the residual expressions required to implement physical transport mechanisms in the MOOSE Framework environment.

\subsection{Model}

A standard thermoelectric device is built of a number of thermoelectric pairs. Each pair consists of a single leg made of an n-type semiconductor, another leg made of a p-type semiconductor and an interconnector usually in the form of a thin copper sheet. The thermoelectric pairs are electrically connected in series and thermally in parallel. It is then possible to assume that electric current of the same value flows through each TE pair while the voltage drop on each single pair equals $1 / n$ fraction of the module supply voltage with $n$ being the number of TE pairs in the module. The parallel thermal connection of the TE pairs allows the assumption that the temperature of the cold side of each pair is equal; the same applies to the temperature of the hot side. 
Although the numerical simulation of the full thermoelectric module does not pose any significant difficulties with modern hardware and software capabilities, it is still beneficial to take advantage of the periodical structure of the TE device and restrict analysis to a single semiconductor pair. Apart from the great reduction of computational effort, such an approach enables a more detailed focus on the physical mechanisms of the problem while still retaining the possibility to infer about the performance of the entire device.

In the present work, a TB-127-1.4-2.9 thermoelectric module manufactured by Kryotherm [14] was taken as a reference example. The device consists of 127 thermoelectric pairs with each semiconductor leg in the form of a cuboid. Each leg is $2.9 \mathrm{~mm}$ high and has a square base with a side dimension of $1.4 \mathrm{~mm}$. Unfortunately, the datasheet does not provide any information about the leg separation distance, but taking into account the external dimensions of the module and the typical layout of the semiconductor legs in the TE device, a value of $1 \mathrm{~mm}$ seems to be the most probable. Similarly, the exact thickness of the copper interconnector in the TB-127-1.4-2.9 module is not known and was estimated to be $0.3 \mathrm{~mm}$.

The computational domain was approximated using $2 \mathrm{D}$ section geometry which may be justified by the fact that the main directions of the gradients of both $T$ and $\varphi$ are expected to be parallel to the height of the semiconductor leg which, in turn, is caused by the fact that the sides of the legs are assumed to be impermeable to electric current and heat flux. The domain geometry of such a problem is shown in Fig. 1.

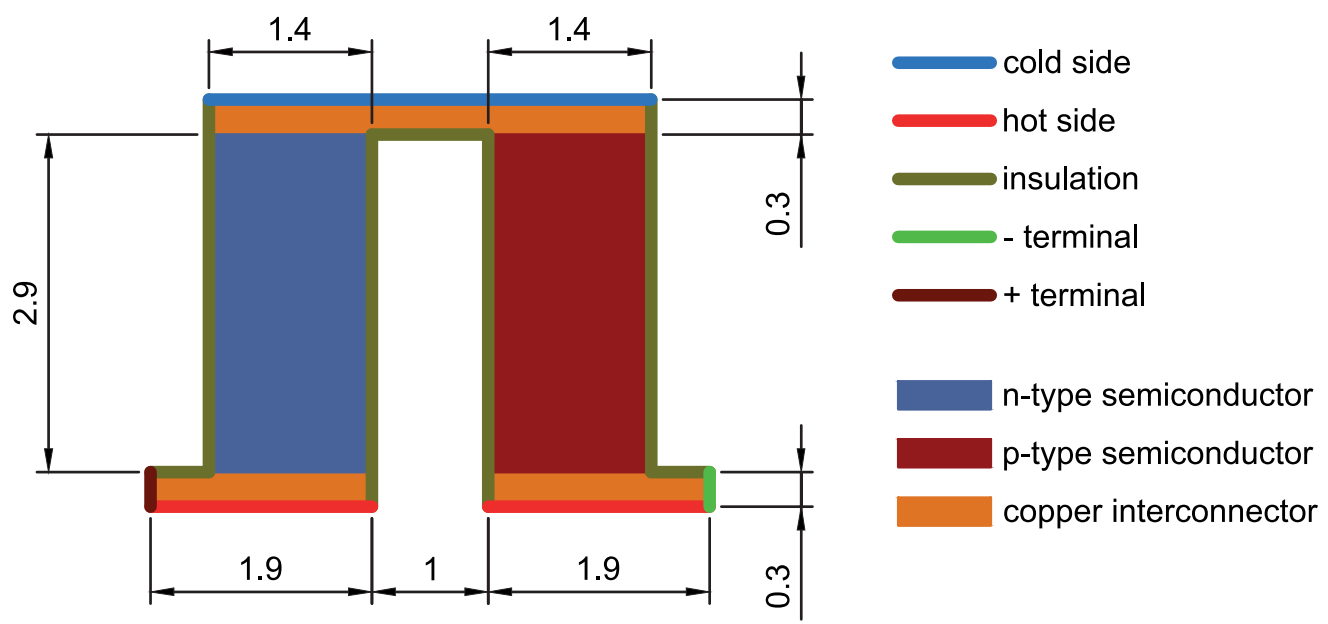

Fig. 1. Problem domain (dimensions in $\mathrm{mm}$ )

Boundary conditions (BCs) for the electric part of the problem include prescribing the value of current density $J$ on the positive terminal and zero potential on the negative terminal. Since the TE pairs are electrically connected in series, the same current will flow through every pair; therefore, the value of $\boldsymbol{J}$ may be simply determined from the device's operational current and the dimensions of the section of the copper interconnector. All other boundaries are electrically insulated by prescribing the $d \varphi / d n=0$ condition. Dirichlet BCs were applied for the thermal part of the problem. The values of temperature on the hot and cold sides of 
the domain were explicitly specified while other boundaries were assumed to be thermally insulated by means of the $\mathrm{d} T / \mathrm{d} \boldsymbol{n}=0$ condition. Although in real world applications the heat transfer between the TE pair and its surroundings should be taken into account, an assumption of the adiabatic lateral surfaces was employed in the present work for simplicity. Such an assumption may be justified by the fact that most of the TE pairs in the module are actually surrounded by other TE pairs with very similar (if not identical) temperature distributions which greatly mitigates heat transfer between them.

The manufacturer's datasheet for the TB-127-1.4-2.9 module lacks information about the semiconductor materials used in this specific device; nevertheless, most contemporary TE devices use bismuth telluride as a thermoelectric material. Therefore, it may be assumed that both $\mathrm{n}$-type and p-type legs are made of properly doped $\mathrm{Bi}_{2} \mathrm{Te}_{3}$. It is important for the model to implement the temperature dependence of material properties, particularly the Seebeck coefficient, since the variation of $\alpha$ with temperature is necessary to describe the Thompson effect. Due to the fact that several different semiconductor alloys based on $\mathrm{Bi}_{2} \mathrm{Te}_{3}$ may have actually been used to manufacture the reference TB-127-1.4-2.9 module, some guesses had to be made. The formulas and data provided in [9] were chosen to approximate the temperature dependence of the thermal conductivity $\lambda$ and Seebeck coefficient $\alpha$ of n-type and p-type semiconductors. Second degree polynomials were used to account for variation of material properties with temperature. The coefficients of the polynomials were found by fitting the experimental data of $\mathrm{Bi}_{2}\left(\mathrm{Te}_{0.94} \mathrm{Se}_{0.06}\right)_{3}$ ( $n$-type) and $\left(\mathrm{Bi}_{0.25} \mathrm{Sb}_{0.75}\right) \mathrm{Te}_{3}$ ( $p$-type). Electrical conductivity $\sigma$ of semiconductor material was inferred from the voltage-current characteristics of TB-127-1.4-2.9 provided in the datasheet as $\sigma=9.694 \cdot 10^{4} \mathrm{Sm}^{-1}$ and independent of temperature. The material properties of the copper interconnector were also taken as independent of temperature with values: $\lambda=400 \mathrm{Wm}^{-1} \mathrm{~K}^{-1}, \sigma=5.88 \cdot 10^{7} \mathrm{Sm}^{-1}, \alpha=6.5 \cdot 10^{-6} \mathrm{VK}^{-1}$.

\section{Solution method}

The coupled system of equations (8) and (9) was solved with Multiphysics ObjectOriented Simulation Environment (MOOSE) Framework [13] released by Idaho National Laboratory under the LGPL 2.1 license. MOOSE, being a framework for numerical software development rather that ready-made application, allows the user to set up any given problem with great flexibility and full control over the solution procedure. The price for that freedom is usually a requirement to write some custom code specific for the physics, boundary conditions or postprocessing. For standard transport equations, however, this is quite straightforward thanks to the very intuitive structure of the framework and the abundance of detailed examples. As the name suggests, MOOSE is intended to tackle multiphysics problems described by coupled systems of partial differential equations; this makes it particularly suitable for the thermoelectric physical phenomena investigated in the present work.

Setting up the problem in MOOSE initially requires the identification of physical mechanisms acting in the computational domain and the boundary conditions. The former are implemented in classes called Kernels on the basis of governing equations (8) and (9) 
stated in a weak form. Similarly, boundary conditions are coded into classes called BCs. The only boundary condition that needed implementation in the present work was the current density $\mathrm{BC}$ on the positive terminal. All the remaining BCs are of the Dirichlet type which is already implemented in the MOOSE Framework by default.

Apart from Kernels and $B C$ s, it is often necessary to introduce some auxiliary functions and tasks into the MOOSE problem definition. The present work makes use of the MOOSE subsystem called Materials to define the temperature dependence of the thermal conductivity $\lambda$ and the Seebeck coefficient $\alpha$ of p-type and n-type semiconductors. The Postprocessors subsystem is utilised to calculate the cooling capacity $\dot{Q}_{c}$ and the electric current $I$ of the module; thus, there is no need to integrate the variables over the cold side and the positive (or negative) terminal in the external software to obtain the $\dot{Q}_{c}$ and $I$ values. Additionally, postprocessors are used to calculate the heat released on the hot side $\dot{Q}_{h}$ and the electric power $P_{e l}$ in order to check the self-consistency of the model on the basis of energy balance $\dot{Q}_{h}=\dot{Q}_{c}+P_{e l}$.

The domain, including the p-type and n-type semiconductors as well as the copper interconnector, was discretised into 26,000 elements of the 4-node rectangular type. The distributions of both electric potential $\varphi$ and temperature $T$ were approximated by means of first order Lagrange shape functions. The steady-state solution was obtained with the Preconditioned Jacobian-Free Newton-Krylov method. On a standard desktop PC with an Intel i7-4770 processor and $8 \mathrm{~GB}$ of RAM, the solution time does not exceed a few seconds.

\section{Results and discussion}

The solution of the problem includes 2D distributions of electric potential $\varphi$ and temperature $T$ within a domain composed of p-type and $n$-type semiconductor legs as well as a copper interconnector. An example solution for the temperature difference between the hot and cold sides $\Delta T=8.87 \mathrm{~K}$ and the electric current $I=2.4 \mathrm{~A}$ is shown in Fig. 2.

As may have been anticipated, the temperature gradient is parallel to the height of the thermoelectric legs; this can be explained by the application of adiabatic boundary conditions on the lateral surfaces of the semiconductors. It is important to note that the observed gradient of $T$ and heat flux calculated on its basis is in fact the result of two main counteracting mechanisms: the Peltier effect, which is the dominant phenomenon responsible for TEC's 'heat pumping' capability that forces heat flux from the cold side towards the hot side and the Fourier conduction, which acts in the opposite direction.

The temperature distribution depicted in Fig. 2 is also affected by the applied material properties of the semiconductors and the interconnector. The different values of $a$ and $\lambda$ for the p-type and n-type semiconductors are responsible for the observed differences in temperature distributions in two legs of the thermoelectric pair, whereas the very low temperature gradient in the interconnector, which is difficult to notice in Fig. 2, is the result of high thermal conductivity of the copper relative to $\lambda$ of semiconductor material. Another important feature of temperature distribution in the thermoelectric pair is that the maximum value of $T$ does not occur on the hot side of the TE device but at some place between the hot 
and cold side which should be attributed to the complex nature of thermoelectric phenomena including internal volume heating by the Joule effect.

The spatial distribution of the electric potential shown in Fig. 2 depicts a potential drop from the positive to the negative terminal without a gradient towards lateral surfaces which is the result of electric insulation boundary condition applied there. The very high electric conductivity of the copper is the cause of the negligible potential variation within the volume of the interconnector material.
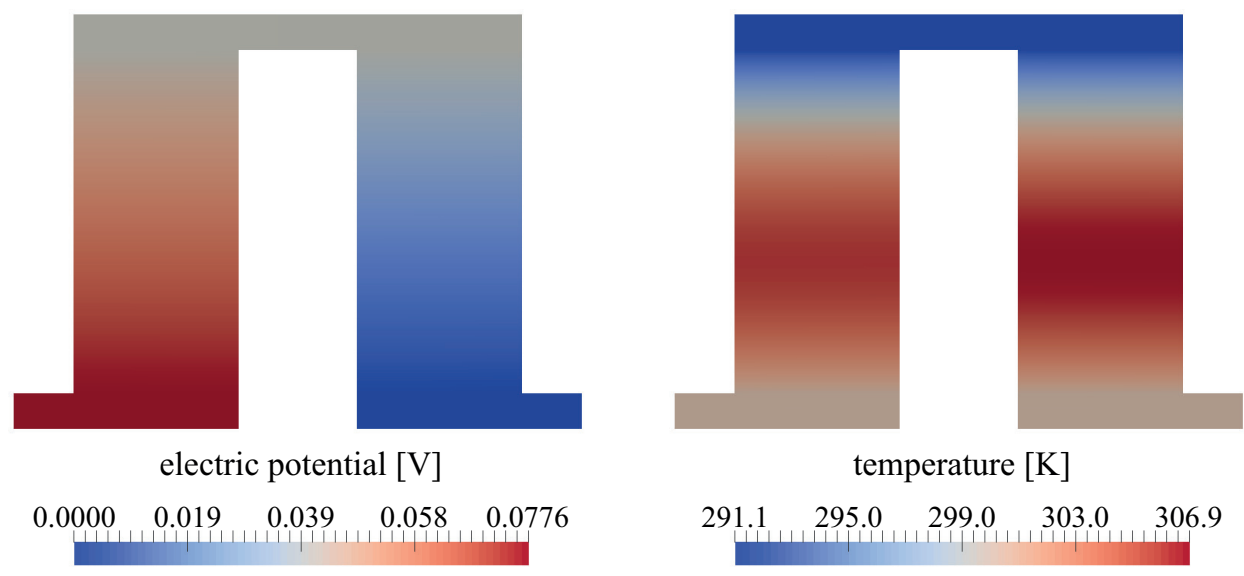

Fig. 2. Spatial distributions of electric potential and temperature in the thermoelectric pair

In order to evaluate the model's ability to reproduce TEC's characteristics for varying supply current and operating temperatures, the numerical results have been compared to data provided by the manufacturer of the device [14]. Figure 3 shows the voltage-current characteristics of the TB-127-1.4-2.9 module. It should be noted that the graph presents the total voltage drop of the module $V$, i.e. the voltage drop of the single TE pair multiplied by the number of thermocouples $n=127$. The dependence of the voltage on the applied current in the reference data is linear and is correctly reproduced in the numerical solution. Close agreement between reference $V$-I curve and numerical data results from the fact that the value of electrical conductivity $\sigma$ used in calculation was inferred from the slope of the $V$-I curves taken from the datasheet. The slope represents electrical resistance of the module; therefore, electrical resistivity and its reciprocal $\sigma$ may be easily estimated with a known length and cross-section area of the semiconductor legs. As can be seen in Fig. 3, the total electrical resistance of the module turns out to be independent of temperature.

Besides the electrical characteristics, the fundamental measure of a thermoelectric cooler's performance is its cooling capacity $\dot{Q}_{c^{\prime}}$, defined as the thermal power that can be absorbed on the cold side. Figure 4 shows cooling capacity as a function of temperature difference for different values of applied electric current. The manufacturer's data states that $\dot{Q}_{c}$ linearly depends on $\Delta T$ and such a trend is clearly visible in the numerical results. Noticeable discrepancies between the obtained solution and the reference data may, however, be observed for points 


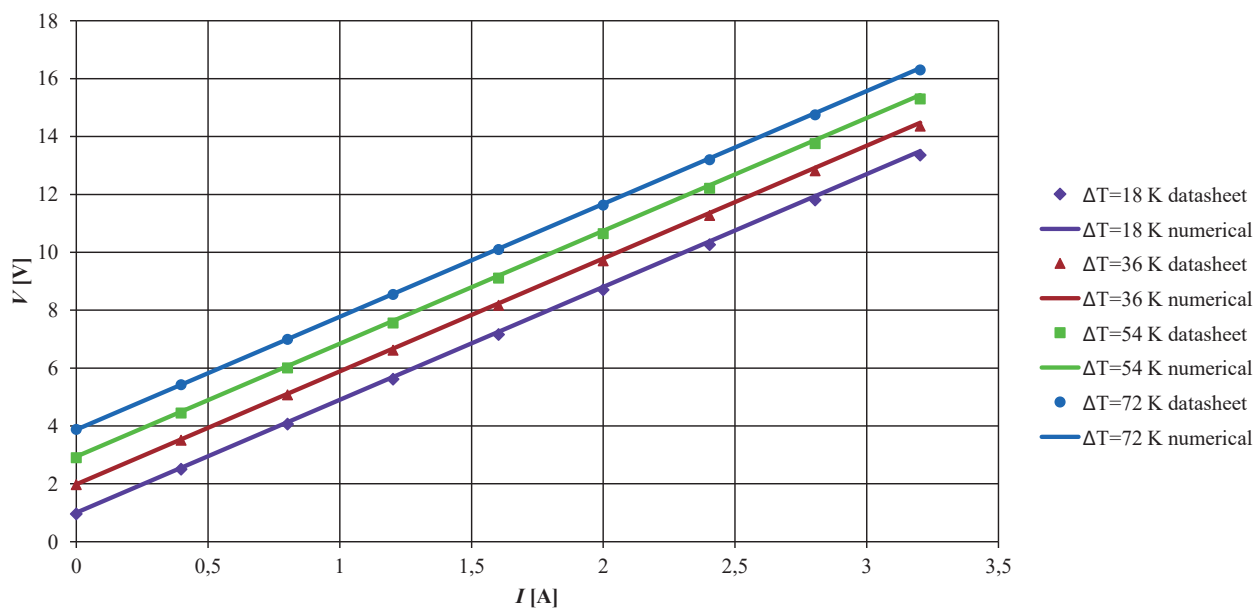

Fig. 3. Voltage-current characteristics of the TE module for different values of temperature difference $\Delta T$

with higher values of electric current and lower temperature differences. Since cold side heat flux is calculated on the surface of the top copper interconnector, it depends on the value of the temperature gradient in that part of the domain. Very high thermal conductivity of the copper results in very low values of this gradient, which may pose a problem for the accurate calculation of heat flux, especially when the overall temperature difference between the cold and hot side of the module is low. Higher values of electric current, on the other hand, cause the more pronounced influence of Joule heating on the thermoelectric phenomena; the maximum value of temperature occurs within the volume of the semiconductor and is greater than the temperature on the hot side - this may further disturb the $\dot{Q}_{c}$ value in comparison to the reference data.

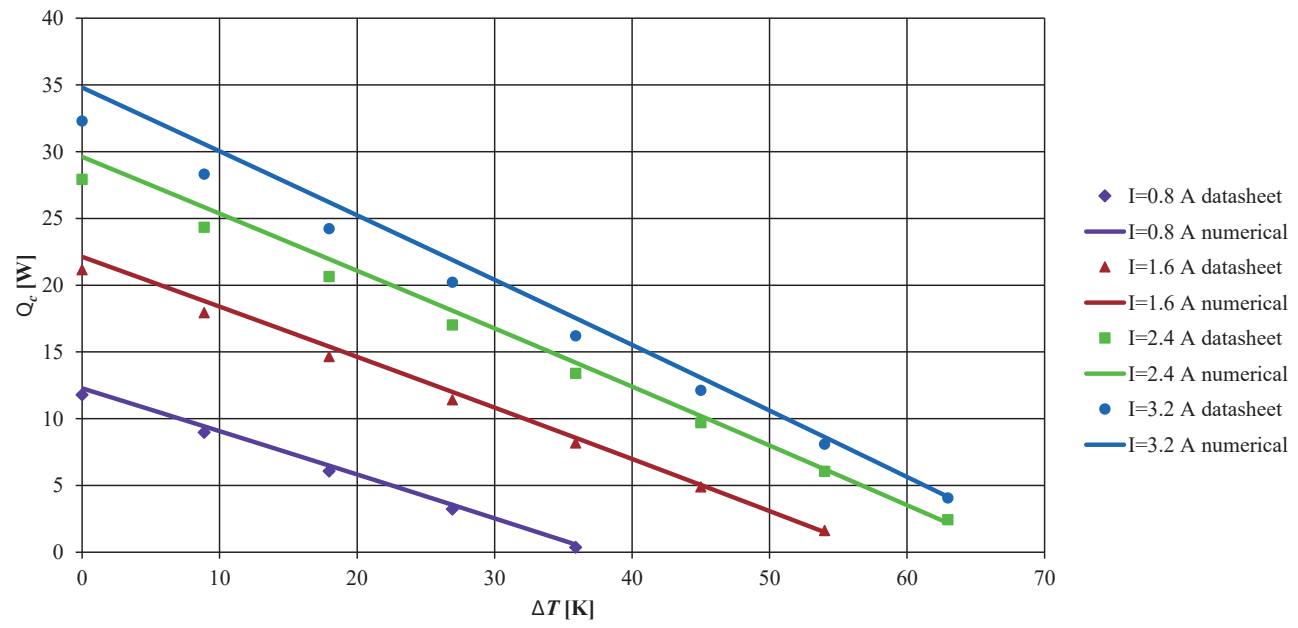

Fig. 4. Cooling capacity as a function of temperature difference for different values of applied electric current 
Another parameter important for the proper description of the thermoelectric cooler's operational characteristics is the coefficient of performance (COP). It is defined as the ratio of cooling capacity to the value of electric power supplied to the module and thus connects the device's electrical and thermal characteristics:

$$
\mathrm{COP}=\frac{\dot{Q}_{c}}{I V}
$$

Figure 5 shows the COP values as a function of the temperature difference for different values of applied electric current. The numerical solution tends to slightly overestimate the COP value which is the effect of the overestimation of $\dot{Q}_{c}$ for low temperature differences and higher currents. Nevertheless, numerical simulation results correctly reproduce reference COP- $\Delta T$ characteristics of the module both in a qualitative and a quantitative sense.

It is important to note that the lack of exact agreement between the numerical results and the reference data may be caused by some assumptions and simplification present in the described model. Firstly, the assumption of complete periodicity of the TE device is not entirely true; thermoelectric pairs near the edge of the device experience heat transfer to the surroundings - this is completely neglected in the present model. The effect of heat transfer between neighbouring thermoelectric pairs on the lateral surfaces of the semiconductor legs was also ignored. Using two-dimensional geometry to describe temperature and electric potential distributions is another simplification since in the real-world case, both distributions would be generally three-dimensional. Finally, there was no data about the semiconductor material that was actually used in the construction of the TB-127-1.4-2.9 module, so both p-type and n-type materials were assumed to be doped bismuth telluride alloys with properties taken from available reference [9].

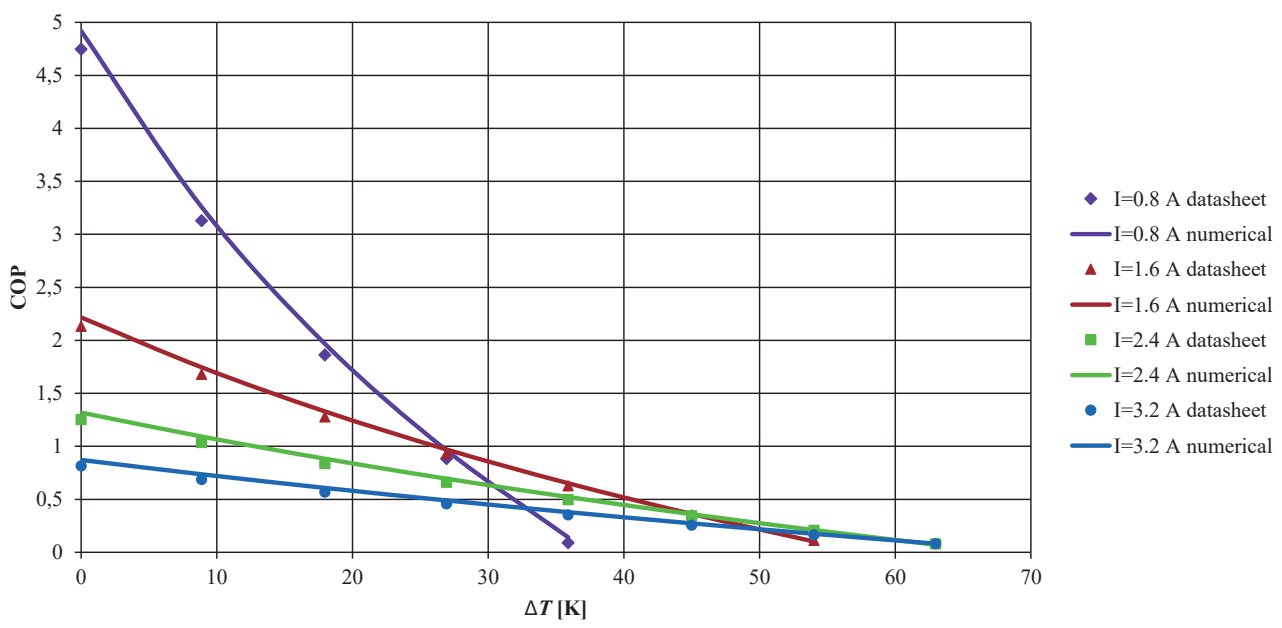

Fig. 5. COP as a function of temperature difference for different values of applied electric current 
The presented comparison between the numerical results and the reference data shows that simplifying assumptions adopted in the model, such as periodicity of the TE cooler, twodimensional approximation and neglecting heat transfer to the surroundings, are valid and may be applied in numerical simulations to assess the performance of the TE device with reasonable accuracy. Introducing full 3D geometry for all thermoelectric pairs in the module and non-adiabatic boundary conditions would probably improve results even further but would certainly require significantly higher computational effort.

\section{Conclusions}

The paper presents a theoretical basis and numerical simulation results of a thermoelectric cooler module. A coupled system of partial differential equations including electric conduction, the Seebeck effect, Peltier and Thomson effects and Joule heating as well as thermal conduction was formulated and transformed into a weak form required for solving it the MOOSE environment. A reference TE device was described by geometry, boundary conditions and material properties. Example simulation results, including spatial distributions of temperature and electric potential within computational domain, were presented along with the voltage-current characteristics and the dependence of cooling capacity and COP on the temperature difference. The obtained results were compared to reference data provided by the device manufacturer. Agreement between the numerical solution and the reference data was good enough to evaluate the model as generally capable of capturing the effects of thermoelectric phenomena present in the TE module. The performance of the model may be further improved by taking into account non-adiabatic boundary conditions on the lateral surfaces of the semiconductor legs and, most importantly, by replacing the $2 \mathrm{D}$ approximation with full three-dimensional geometry.

\section{References}

[1] Zhao D., Tan G., A review of thermoelectric cooling: Materials, modeling and applications, Applied Thermal Engineering, 66, 2014, 15-24.

[2] Wang P., Recent advance in thermoelectric devices for electronics cooling, [in:] Cooling of Microelectronic and Nanoelectronic Equipment: Advances and Emerging Research, eds. Iyengar M., Geisler K.J.L., Sammakia B., World Scientific Publishing, Singapore 2015, 167-194.

[3] Li C., Jiao D., Mohan H., Guo F., Wang J., Thermoelectric cooling for power electronics circuits: Modeling and applications, Twenty-Eighth Annual IEEE Applied Power Electronics Conference and Exposition (APEC), Long Beach, California, 2013, 32753282.

[4] Putra N., Ardiyansyah, Sukyono W., Johansen D., Iskandar F.N., The characterization of a cascade thermoelectric cooler in a cryosurgery device, Cryogenics, 50, 2010, 759-764. 
[5] Vollmer M., Möllmann K.-P., Infrared Thermal Imaging, WILEY-VCH, Weinheim 2010.

[6] Mansour K., Qiu Y., Hill C.J., Soibel A., Yang R.Q. Mid-infrared interband cascade lasers at thermoelectric cooler temperatures, Electronics Letters, 42(18), 2006, 1034-1035.

[7] Kustas A., Jurgensmeyer A., Williams D., Dickman B., Bradley T., Willams J., Cote T., Lipsey T., Minor B., High efficiency thermoelectric coolers for use in firefighter applications, 10th International Energy Conversion Engineering Conference (IECEC), Georgia, Atlanta 2012.

[8] Oliveira K.S.M., Cardoso R.P., Hermes C.J.L., Two-dimensional modeling of thermoelectric cells, 15th International Refrigeration and Air Conditioning Conference, Indiana, West Lafayette 2014.

[9] Wang X.-D., Huang Y.-X., Cheng C.-H., Ta-Wei Lin D., Kang C.-H., A three-dimensional numerical modeling of thermoelectric device with consideration of coupling of temperature field and electric potential field, Energy, 47(1), 2012, 488-497.

[10] Chen W.-H., Liao C.-Y., Hung C.-I, A numerical study on the performance of miniature thermoelectric cooler affected by Thomson effect, Applied Energy, 89(1), 2012, 464-473.

[11] Antonova E.E., Looman D.C., Finite elements for thermoelectric device analysis in ANSYS, 24th International Conference on Thermoelectrics, Clemson, South Carolina, 2005, 215-218.

[12] Ebling D., Jaegle M., Bartel M., Jacquot A., Böttner H., Multiphysics simulation of thermoelectric systems for comparison with experimental device performance, Journal of Electronic Materials, 38(7), 2009, 1456-1461.

[13] Gaston D., Newman C., Hansen G., Lebrun-Grandié D., MOOSE: A parallel computational framework for coupled systems of nonlinear equations, Nuclear Engineering and Design, 239, 2009, 1768-1778.

[14] http://www.kryotherm.com/modulez/down57d0.pdf?filename=/dir2attz/import/ TB-127-1.4-2.9.pdf (access: 02.01.2018).

[15] Heat Transfer Module User's Guide, COMSOL Multiphysics ${ }^{\circledast}$ v. 5.1. COMSOL AB, Stockholm 2015.

[16] Lee H., The Thomson effect and the ideal equation on thermoelectric coolers, Energy, 56, 2013, 61-69. 